\title{
Design of Peptidic Foldamer Helices: A Stereochemical Patterning Approach**
}

\author{
István M. Mándity, Edit Wéber, Tamás A. Martinek, * Gábor Olajos, Gábor K. Tóth, Elemér Vass, \\ and Ferenc Fülöp*
}

Folded polymers are utilized in virtually all vital processes in nature. Non-natural folded polymers (foldamers) have the potential for being similarly or even more versatile, and the design of such molecules is of considerable current interest. ${ }^{[1]}$ In this respect, $\beta$ - and chimera $\alpha \beta$-peptides are perhaps the best characterized foldamers, ${ }^{[2]}$ as they form a number of residue-controlled secondary structures, which have been used for various biological applications ${ }^{[3]}$ and to create nanostructured materials. ${ }^{[4]}$ The folding procedure is influenced by many factors, such as the residue type, the side-chain topology and chemistry, the pattern of hydrophobic regions along the backbone, the solvent, etc. ${ }^{[5]}$ For peptidic foldamers, the backbone stereochemistry plays a key role in the formation of the secondary structure. ${ }^{[6]}$ For $\beta$-peptides correlations have been revealed between the stereochemistry of the residues and the secondary structure: a change in the relative stereochemistry within the $\beta$ residues effectively changes the secondary structure, which can be either a helix or a strand. ${ }^{[7]}$ For $\alpha$-peptides, a systematic tuning of the secondary structure is also possible by using a specific stereochemical pattern (e.g., DL- $\alpha$-amino acid stabilized $\beta$ helix and $\alpha$ strand $).{ }^{[5-e, 8]}$ The use of stereochemical patterning along the backbone and simultaneous variation of the residue types ( $\alpha$ and $\beta$ residues) can lead to novel periodic secondary structures. Herein we show that the stereochemical patterning yields a simple, intuitive foldamer design tool and furnishes a highly effective de novo construction methodology for generating peptidic foldamers having tailored properties and potential biological activities.

[*] I. M. Mándity, E. Wéber, Dr. T. A. Martinek, G. Olajos,

Prof. Dr. G. K. Tóth, Prof. Dr. F. Fülöp

Institutes of Pharmaceutical Chemistry and Medical Chemistry

Universitiy of Szeged, 6720 Szeged, Eötvös u. 6 (Hungary)

Fax: (+36) 62-545-705

E-mail:martinek@pharm.u-szeged.hu

fulop@pharm.u-szeged.hu

Homepage: http://www.pharm.u-szeged.hu/gyki http://www.pharm.u-szeged.hu/gyki

Dr. E. Vass

Department of Organic Chemistry, Eötvös Loránd University 1117 Budapest, Pázmány P. s. 1A (Hungary)

[**: We thank the Hungarian Research Foundation (NF69316 and T 049792) and GVOP-KMA (3.2.1-2004-04-0345/3.0) for financial support. T.A.M. acknowledges the János Bolyai Fellowship from the HAS. The computational resources of HPC U-Szeged (ALAP4. 00092/2005) are acknowledged.

을

Supporting information for this article is available on the WWWW under http://dx.doi.org/10.1002/anie.200805095.
The effects of the stereochemistry of the residues on the overall geometry of the peptide are conveyed through the local torsional preferences and the side chain-backbone interactions. ${ }^{[2]}$ Therefore, the torsional requirements within the peptide backbone for various H-bond-stabilized periodic secondary structures ${ }^{[1,3,6-12]}$ were studied first. The $\phi$ and $\psi$ torsions were analyzed according to the Ramachandran ${ }^{[13]}$ and Balaram ${ }^{[14]}$ definitions for the $\alpha$ and $\beta$ residues, respectively. Although the $\beta$ residues contain an additional dihedral angle $\theta\left(\mathrm{N}-\mathrm{C}_{\beta}-\mathrm{C}_{\alpha}-\mathrm{CO}\right), \theta$ is dependent on $\phi$ and $\psi$, and its gauche conformation is inherently stable, as demonstrated by thorough analyses. ${ }^{[15]}$

The dihedral angle pattern for the repeating units revealed that the signs of the torsions flanking the amide moiety $(\psi][\phi$, where ][ designates the $\mathrm{CONH}$ group) are crucial with respect to the type of induced secondary structure, and the signs also determine the orientation of amides within the helices. The observed rules are summarized in Table 1 (for the original data utilized for this analysis see Table S1 in the Supporting Information).

Table 1: The secondary structure preference of the $\psi][\phi$ building blocks.

\begin{tabular}{lll}
\hline Signs of $\psi][\phi$ & $\begin{array}{l}\text { Secondary } \\
\text { structure }\end{array}$ & $\begin{array}{l}\text { Amide orientation in } \\
\mathrm{P} \text { and } \mathrm{M} \text { helices }\end{array}$ \\
\hline+$][+$ & helix & $\mathrm{P}:$ parallel; $\mathrm{M}$ : antiparallel \\
$-][-$ & helix & $\mathrm{P}:$ antiparallel; $\mathrm{M}$ : parallel \\
$+][-$ & strand & \\
$-][+$ & strand &
\end{tabular}

[a] $\mathrm{NH}$ to $\mathrm{O}=\mathrm{C} \mathrm{H}$-bond orientations relative to the $\mathrm{N}$-terminal to $\mathrm{C}$ terminal direction. $\mathrm{P}=$ right-handed helix, $\mathrm{M}=$ left-handed helix.

Since a helix (by definition) has a fixed overall helicity along a sequence, and it requires stabilizing hydrogen bonds between identically oriented amide moieties at periodic distances, the sequence of the $\psi][\phi$ signs must also exhibit a periodic pattern. If a helix is stabilized by $i-i+n$ peptide bond contacts, then the $\psi][\phi$ pattern starting from position $i$ should be identical to that starting at $i+n$. The homochiral helices having uniformly oriented amides, and the alternating heterochiral helices having alternating amide orientations are special cases of the class of periodic $\psi][\phi$ sign sequences.

The stereochemistry of the polypeptide chain ${ }^{[2,13]}$ reveals a correlation between the signs of the torsions and the absolute configurations of the residues (Table 2). This correlation was established by replacing side-chain groups with a methyl group to retain the CIP (Cahn-Ingold-Prelog) designation for identical spatial arrangements. Structures of the peptidic 
Table 2: Signs of dihedral angles $([\psi$ and $\phi])$ induced by the configurations of the backbone atoms.

\begin{tabular}{lll}
\hline Residue type & Backbone configuration & Structuring effect \\
\hline$\alpha$ & $(S)-C_{\alpha}$ & {$[-$} \\
$\alpha$ & $(R)-C_{\alpha}$ & {$[+$} \\
$\beta$ & $(S)-C_{\alpha}$ & {$[-$} \\
$\beta$ & $(R)-C_{\alpha}$ & {$[+$} \\
$\beta$ & $(S)-C_{\beta}$ & $-]$ \\
$\beta$ & $(R)-C_{\beta}$ & $+]$ \\
\hline
\end{tabular}

sequences containing unsubstituted or $\alpha, \alpha$-dialkyl-substituted residues suggests that the adjacent torsion angles tend to accommodate helix formation. ${ }^{[16,17]}$

To test the predictive ability of the above relationships in a de novo helix design, $\psi][\phi$ sequences and the corresponding stereochemical patterns were assembled (1-3, Figure 1). Sequences for 4-6 were designed to disrupt the like junctions and the periodic $\psi][\phi$ patterns in the central region. Stereochemical patterning was used for the whole sequence, and the designed sequences were compiled into real $\beta$ - and $\alpha \beta$-peptides by using ACPC $(\mathrm{ACPC}=$ cis-2-aminocyclopentanecarboxylic acid) diastereomers, $\beta 3$-amino acids, and $\alpha$ amino acid enantiomers having the appropriate absolute configurations. The side-chain stereochemistry was chosen so as to permit advantageous interactions between the juxtaposed residues and to introduce biomimetic proteinogenic side chains.

A hybrid Monte Carlo (MC)/molecular dynamics (MD) conformational search was carried out through molecular mechanics $^{[18]}$ without using any distance restraints. The resulting families having the lowest-energy conformations for 1-3 indicated helical conformations. For 4-6, meandering backbone geometry derived from turn-like segments was detected in the low-energy conformations, which lacked any long-range order. The lowest-energy conformers from the simulations of 1-3 were additionally optimized at the ab initio quantum chemical level of theory. The structure optimizations converged properly, and novel foldameric helices were found. For $\mathbf{1}$ and 2, the left-handed (M) helix is stabilized by concatenated 14- and 16-membered H-bonded pseudorings (H14-16, Figure 2a), whereas 2 exhibits a potential salt-bridge interaction between the juxtaposed side chains. For $\mathbf{3}$, the lefthanded (M) helix is stabilized by consecutively concatenated 9-, 10-, 11-, and 12-membered pseudorings in a repeating unit (H9-12, Figure 2b). The amide orientations display the desired pattern in all the structures.

Compounds 2, 3, 5, and $\mathbf{6}$ were synthetized on a solid support and the purified products were characterized by RPHPLC, MS, and various NMR methods using different solvents; namely $8 \mathrm{~mm}$ solutions each in $\mathrm{CD}_{3} \mathrm{OH}$, [D 6 DMSO, and water $\left(\mathrm{H}_{2} \mathrm{O} / \mathrm{D}_{2} \mathrm{O}\right.$ 90:10). The NMR signal dispersions were good for $\mathbf{2}$ and $\mathbf{3}$ and resonance broadening was not observed. The resonance assignments were carried out at $277 \mathrm{~K}$, the temperature at which the best signal resolutions were obtained. For $\mathbf{5}$ and $\mathbf{6}$, the signal dispersions were poorer, especially in the $\mathrm{C}_{\alpha} \mathrm{H}$ and $\mathrm{C}_{\beta} \mathrm{H}$ regions; this was also the case at lower temperature, indicating the absence of

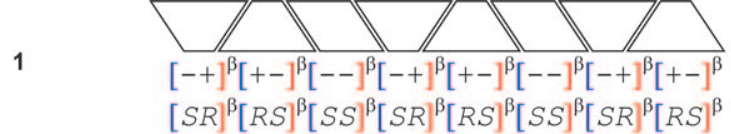

2
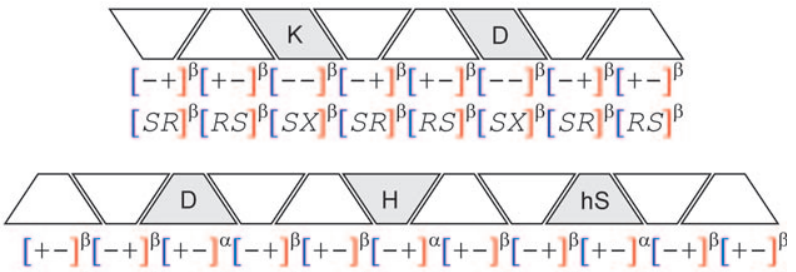
$[R S]^{\beta}[S R]^{\beta}[R]^{\alpha}[S R]^{\beta}[R S]^{\beta}[S]^{\alpha}[R S]^{\beta}[S R]^{\beta}[R]^{\alpha}[S R]^{\beta}[R S]^{\beta}$

4

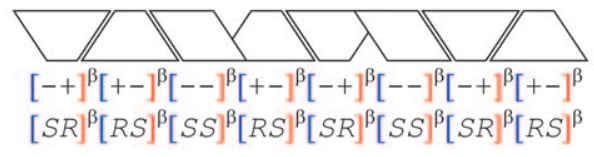

5

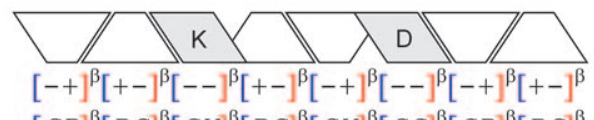

$[S R]^{\beta}[R S]^{\beta}[S X]^{\beta}[R S]^{\beta}[S X]^{\beta}[S S]^{\beta}[S R]^{\beta}[R S]^{\beta}$

6
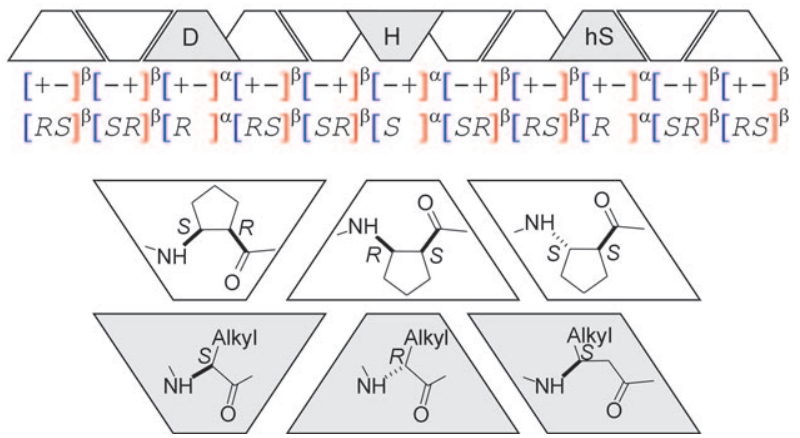

Figure 1. The de novo designed $\beta$ - and $\alpha \beta$-peptide sequences based on the $\psi][\phi$ sign, stereochemical patterns, and their quasi-randomized controls. The side chains are indicated by the single letter codes ( $\mathrm{hS}=$ homo-serine). The configurations are indicated in the CIP system with $\mathrm{Alkyl}=$ methyl, $X=$ undefined stereochemistry.

periodic secondary structures, therefore making the resonance assignments only partially possible. The chemical shifts of the backbone amide $\mathrm{NH}$ groups of $\mathbf{2}$ were measured for a temperature gradient $\left(\Delta \delta \Delta T^{-1}\right)$ in $\left[\mathrm{D}_{6}\right] \mathrm{DMSO}$, and they were generally above $-5 \mathrm{ppb} \mathrm{K}^{-1}$ (see Figure S5a in the Supporting Information); the highest value was observed at the central part of the sequence $\left(-3.86 \mathrm{ppbK}^{-1}\right.$ for NH5) indicating shielding from the solvent. ${ }^{[19-21]}$ Sequence 5 displays a $\Delta \delta$ $\Delta T^{-1}$ less than $-5 \mathrm{ppbK}^{-1}$, which supports the structure breaking effect of the disrupted stereochemical pattern. The exception is $\mathrm{NH} 4$ wherein $\Delta \delta \Delta T^{-1}$ increased in $\mathbf{5}$ as compared with that of $\mathbf{2}$, which is attributed to the proximity of the Lys side chain potentially acting as a H-bond acceptor for NH4. For 3, strongly shielded amides were found (see Figure S5b in the Supporting Information). The disrupted stereochemical pattern in 6 resulted in lower $\Delta \delta \Delta T^{-1}$ values in the middle part of the sequence, indicating the presence of impaired hydrogen bonds. However, strong hydrogen bonds are observed for $\mathrm{NH} 4$ and $\mathrm{NH} 10$, which suggest a partially ordered structure different from that of $\mathbf{3}$. 


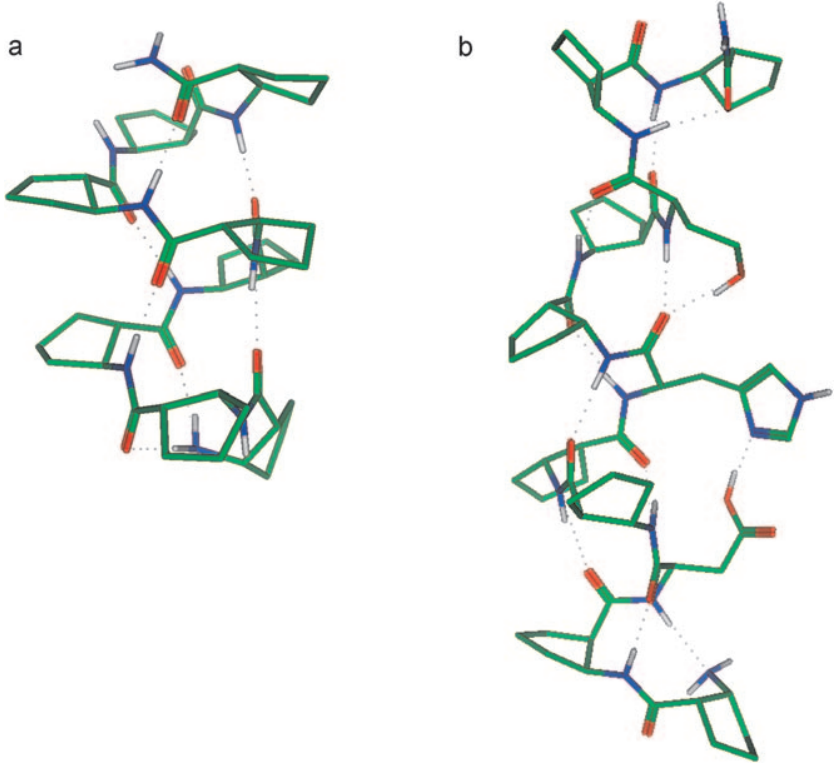

Figure 2. Helical conformations predicted by molecular modeling for 1 (a) and 3 (b).

Thorough evaluation of the ROESY spectra revealed a number of $i-i+2$ and $i-i+3$ interactions for $\mathbf{2}$ and $\mathbf{3}$ (Table 3). For $\mathbf{5}$ and $\mathbf{6}$, mainly sequential and intra-residue NOE data were found. Structures were refined by using

Table 3: Number of resolved NOE interactions for the studied models.

\begin{tabular}{lrrrr}
\hline Type of NOE & $\mathbf{2}$ & $\mathbf{3}$ & $\mathbf{5}$ & $\mathbf{6}$ \\
\hline intra-residue & 27 & 21 & 3 & 9 \\
$i-i+1$ & 19 & 16 & 7 & 9 \\
$i-i+2$ & 5 & 6 & 0 & 0 \\
$i-i+3$ & 4 & 5 & 0 & 1 \\
\hline
\end{tabular}

NOE-derived distance restraints ${ }^{[6 \mathrm{e}]}$ and a hybrid MC/MD conformational sampling. The cluster analysis of the $10^{4}$ conformations revealed two conformational families for $\mathbf{2}$, both exhibiting the overall H14-16 fold with equally low energy and root-mean-square violations (RMSV $=0.003 \AA$ for the lowest energy structures). The difference between the two clusters was the fraying C-terminal, which is because of the hydrogen bonding between the terminal amide and the $\beta$ h-Asp side chain. The $\mathrm{NH}-\mathrm{C}_{\beta} \mathrm{H}$ and $\mathrm{NH}-\mathrm{C}_{\alpha} \mathrm{H}$ vicinal couplings were uniformly greater than $8.5 \mathrm{~Hz}$, in accord with the helical conformation. For $\mathbf{3}$, a single conformational family was found, corresponding to the H9-12 helix (RMSV $=0.010 \AA$ for the best structure). The $\mathrm{NH}-\mathrm{C}_{\beta} \mathrm{H}$ vicinal couplings measured for the $\beta$ residues were greater than $9.0 \mathrm{~Hz}$, while the ${ }^{3} J\left(\mathrm{NH}-\mathrm{C}_{\alpha} \mathrm{H}\right)$ values for the $\alpha$ residues were around $7.5 \mathrm{~Hz}$. These values are in line with the H9-12 helix geometry, which requires that the $\alpha$ residues attain a smaller $\mathrm{NH}-\mathrm{C}_{\alpha} \mathrm{H}$ torsion than the $\beta$ residues at the $\mathrm{NH}-\mathrm{C}_{\beta} \mathrm{H}$ dihedral. No consistent violations of the distance restraints were observed and the NOE data predicted by the ten lowest energy conformations were detected in the spectra.
In the absence of a sufficient number of long-range restraints, the standard structure refinement was not possible for 5 and $\mathbf{6}$. The single $i-i+3$ NOE ( $\left.\mathrm{NH} 9-\mathrm{C}_{\alpha} \mathrm{H} 6\right)$ for $\mathbf{6}$ defines a turn in the central segment, thereby leading to loop-like overall geometry (see the Supporting Information).

Electronic circular dichroism (ECD) spectra were run at room temperature and, for consistence with the NMR analysis, at $277 \mathrm{~K}$ too; no significant difference in the ECD values was found, except for the slightly increased intensities for the Cotton effects detected for $\mathbf{2}$ and $\mathbf{3}$ (Figure 3). The

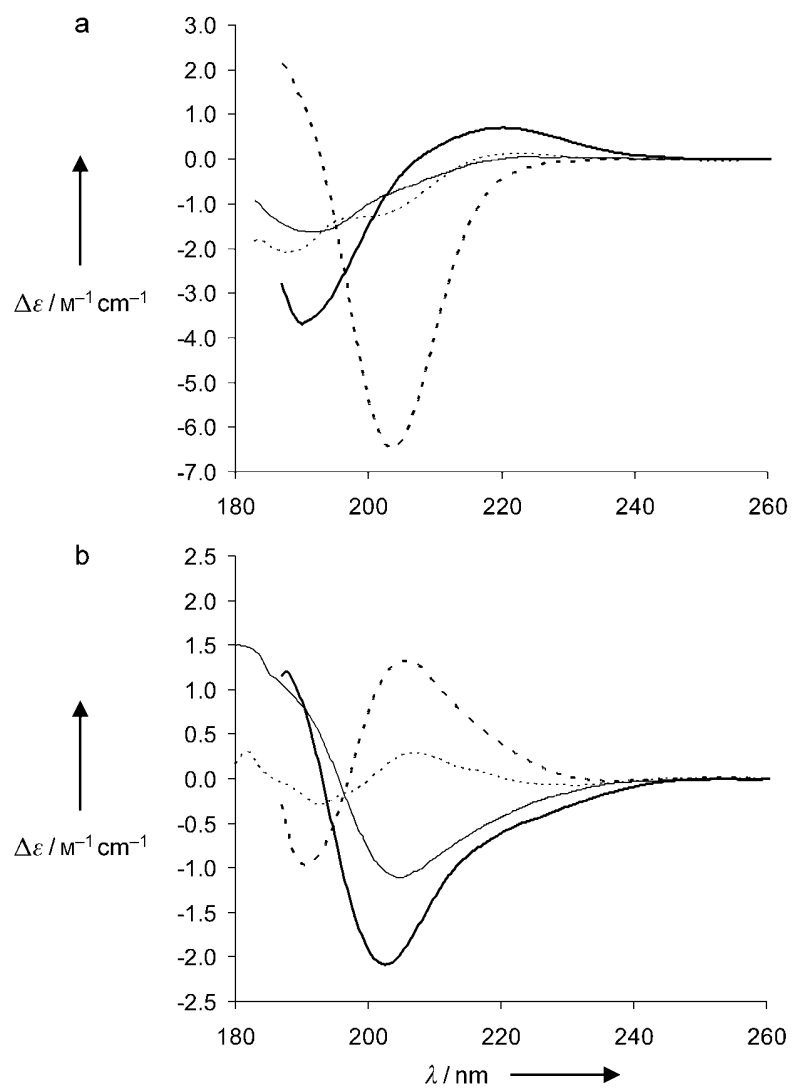

Figure 3. ECD curves measured at room temperature in methanol (thick curves) and water (thin curves). a) For $\mathbf{2}$ (solid) and $\mathbf{5}$ (dashes). b) For $\mathbf{3}$ (solid) and $\mathbf{6}$ (dashes). Data were normalized to unit chromophore.

disrupted structure $\mathbf{5}$ exhibits an asymmetric low wavelength Cotton effect having a sign opposite to that of 2 . The extensive change in the ECD fingerprint indicates that the H14-16 helix is destroyed. For 6, the altered stereochemical pattern caused a complete change in the ECD fingerprint relative to 3 . The inverted symmetric Cotton effect might be attributed to the loop-like organization, which is supported by the NMR and modeling results. The ECD curve recorded in water furnished convincing evidence of the stability of the H9-12 helix of $\mathbf{3}$, because the same features can be observed, though with decreased intensities. The H14-16 helix of 2 partially retains its spectral features even in the aqueous environment in which the hydrogen bonds are destroyed, but the fall in the intensity is significant. $\mathbf{5}$ and $\mathbf{6}$ display either a 
great intensity loss or a complete difference in the ECD spectra in water, thereby corroborating the absence of the stable long-range organization.

These results suggest that the homochiral and the alternating heterochiral systems do not permit access to all possible periodic secondary structures. Herein, the necessary requirements for helix formation in peptidic sequences were postulated and experimentally tested in terms of stereochemical patterns. Similar to analogue computers, the absolute configurations of each residue can serve as binary codes for the basic instruction set in the assembly language of the peptidic foldamer sequences. Notably, however, the proposed methodology is based on a set of geometrical requirements of the periodic secondary structure formation, but the design method cannot handle all the conditions required for folding in solution. Testing of the limitations of this promising approach requires additional experimental and theoretical analyses.

\section{Experimental Section}

Peptide synthesis: Peptide oligomers 2, 3, 5, and $\mathbf{6}$ were synthetized by a standard solid-phase technique, utilizing $9 H$-fluoren-9-ylmethoxycarbonyl (Fmoc) chemistry. The crude reaction mixture was purified by RP-HPLC methods and the appropriate fractions were combined and lyophilized (see the Supporting Information for details). The peptides were characterized by analytical RP-HPLC analysis and mass spectrometry. The measured molecular weights were as follows: $2 \mathrm{~m} / z[M+\mathrm{H}]=956.1, \quad m / z[M+2 \mathrm{H}]^{2+}=478.6 ; 3 \mathrm{~m} / z[M+\mathrm{H}]^{+}=$ $1259.8, \quad \mathrm{~m} / z[M+2 \mathrm{H}]^{2+}=630.5 ; \quad \mathbf{5} \quad \mathrm{m} / \mathrm{z}[\mathrm{M}+\mathrm{H}]=956.0, \quad \mathrm{~m} / \mathrm{z}$ $[M+2 \mathrm{H}]^{2+}=478.5 ; 6 \mathrm{~m} / z[M+\mathrm{H}]^{+}=1259.9, \mathrm{~m} / z[M+2 \mathrm{H}]^{2+}=630.6$.

NMR experiments: NMR measurements were performed on a Bruker Avance III $600 \mathrm{MHz}$ spectrometer having a triple resonance $2.5 \mathrm{~mm}$ capillary probe with $z$-gradient coil in different solvents; $8 \mathrm{~mm}$ solutions each in $\mathrm{CD}_{3} \mathrm{OH},\left[\mathrm{D}_{6}\right] \mathrm{DMSO}$ and water $\left(\mathrm{H}_{2} \mathrm{O}: \mathrm{D}_{2} \mathrm{O}\right.$ 90:10) at $296.1 \mathrm{~K}, 277.1 \mathrm{~K}$, and $273.1 \mathrm{~K}$. The ROESY measurements were performed using a WATERGATE solvent suppression scheme. For the ROESY spinlock, 225 and $400 \mathrm{~ms}$ mixing times were used, and the number of scans taken was 64. The TOCSY measurements were performed with homonuclear Hartman-Hahn transfer with the MLEV17 sequence, with an $80 \mathrm{~ms}$ mixing time, and the number of scans taken was 32 . For all the $2 \mathrm{D}$ spectra $2 \mathrm{~K}$ time domain points and 512 increments were applied. The processing was carried out by using a cosine-bell window function, single-zero filling, and automatic baseline correction.

ECD experiments: CD spectra were measured on a Jasco J810 dichrograph at $298 \mathrm{~K}$ in a $0.02 \mathrm{~cm}$ cell and at $277 \mathrm{~K}$ in a $0.1 \mathrm{~cm}$ cell. Eight spectra were accumulated for each sample. The baseline spectrum recorded for the solvent only was subtracted from the raw data. The concentrations of the sample solutions were $1 \mathrm{~mm}$ for the $0.02 \mathrm{~cm}$ cell and $5 \mathrm{~mm}$ for the $0.1 \mathrm{~cm}$ cell. The data were normalized for the number of chromophores.

Modeling: Molecular mechanical simulations were carried out in the Chemical Computing Group's Molecular Operating Environment (MOE). For the energy calculations, the MMFF94x force field was used, without a cutoff for van der Waals and Coulomb interactions, and the distance-dependent dielectric constant ( $\varepsilon r$ ) was set to $\varepsilon=1.8$ (corresponds to $\mathrm{CH}_{3} \mathrm{OH}$ ). The conformational sampling was carried out by using the hybrid Monte Carlo (MC)/molecular dynamics (MD) simulation (as implemented in MOE) at $300 \mathrm{~K}$ with a random MC sampling step after every 10 MD steps. The MC-MD was run with a step size of 2 fs for $20 \mathrm{~ns}$, and the conformations were saved after every 1000 MD steps, which resulted in $10^{4}$ structures. For the NMR restrained simulation, the upper distance limits were calculated by using the isolated spin pair approximation and classified by the following standard method (strong: $2.5 \AA$, medium: $3.5 \AA$, and weak 5.0 $\AA$ ). The lower limit was set to $1.8 \AA$. Restraints were applied as a flat-bottomed quadratic penalty term with a force constant of $5 \mathrm{kcal}^{-2}$. The final conformations were minimized to a gradient of $0.05 \mathrm{kcalmol}^{-1}$ and the minimization was applied in a cascade manner, using the steepest-descent, conjugate gradient, and truncated Newton algorithm. For the ab initio calculations, the optimizations were carried out with the Gaussian03 program: first at the HF/3-21G level, and then by using density-functional theory at the B3LYP/6$311 \mathrm{G}^{* *}$ level with a default set-up. Optimizations were performed with the Polarizable Continuum Model $\left(\mathrm{CH}_{3} \mathrm{OH}\right)$ also at the B3LYP/ 6-31G* level.

Received: October 17, 2008

Revised: January 8, 2009

Published online: February 11, 2009

Keywords: amino acids - foldamers - helical structures · NMR spectroscopy $\cdot$ peptides

[1] a) D. H. Appella, L. A. Christianson, D. A. Klein, D. R. Powell, X. L. Huang, J. J. Barchi, S. H. Gellman, Nature 1997, 387, 381 384; b) P. Le Grel, G. Guichard in Foldamers: Structure, properties and applications: foldamers based on remote intrastrand interactions (Eds.: S. Hecht, I. Huc), Wiley-VCH, Weinheim, 2007, pp. 35-74; c) C. M. Goodman, S. Choi, S. Shandler, W. F. DeGrado, Nat. Chem. Biol. 2007, 3, 252-262; d) D. Seebach, A. K. Beck, D. J. Bierbaum, Chem. Biodiversity 2004, 1, 1111-1239.

[2] a) T. A. Martinek, F. Fülöp, Eur. J. Biochem. 2003, 270, 36573666 ; b) Y. D. Wu, W. Han, D. P. Wang, Y. Gao, Y. L. Zhao, Acc. Chem. Res. 2008, 41, 1418-1427; c) R. P. Cheng, Curr. Opin. Struct. Biol. 2004, 14, 512-520.

[3] a) P. I. Arvidson, N. S. Ryder, H. M. Weiss, G. Gross, O. Kretz, R. Woessner, D. Seebach, ChemBioChem 2003, 4, 1345-1347; b) E. P. English, R. S. Chumanov, S. H. Gellman, T. J. Compton, J. Biol. Chem. 2006, 281, 2661-2667; c) E. A. Porter, X. Wang, H. Lee, B. Weisblum, S. H. Gellman, Nature 2000, 404, 565-565; d) J. A. Kritzer, N. W. Luedtke, E. A. Harker, A. Schepartz, J. Am. Chem. Soc. 2005, 127, 14584-14585; e) J. A. Kritzer, J. D. Lear, M. E. Hodsdon, A. Schepartz, J. Am. Chem. Soc. 2004, 126, 9468 -9469; f) D. Liu, W. DeGrado, J. Am. Chem. Soc. 2001, 123, $7553-7559$.

[4] a) T. A. Martinek, A. Hetényi, L. Fülöp, I. M. Mándity, G. K. Tóth, Imre Dékány, F. Fülöp, Angew. Chem. 2006, 118, $2456-$ 2460; Angew. Chem. Int. Ed. 2006, 45, 2396-2400; b) F. Rua, S. Boussert, T. Parella, I. Diez-Perez, V. Branchadell, E. Giralt, R. M. Ortuno, Org. Lett. 2007, 9, 3643-3645.

[5] a) E. H. C. Bromley, K. Channon, E. Moutevelis, D. N. Woolfson, ACS Chem. Biol. 2008, 3, 38-50; b) K. A. Dill, Protein Sci. 1999, 8, 1166-1180; c) J. Venkatraman, S. C. Shankaramma, P. Balaram, Chem. Rev. 2001, 101, 3131-3152; d) S. Rana, B. Kundub, S. Durani, Chem. Commun. 2004, 2462-2463; e) S. Rana, B. Kundub, S. Durani, Chem. Commun. 2005, 207-209; f) L. Baltzer, H. Nilsson, J. Nilsson, Chem. Rev. 2001, 101, 3153 3163.

[6] a) D. Seebach, S. Abele, K. Gademann, G. Guichard, T. Hintermann, B. Jaun, J. L. Matthews, J. V. Schreiber, L. Oberer, U. Hommel, H. Widmer, Helv. Chim. Acta 1998, 81, $932-982$; b) K. Ananda, P. G. Vasudev, A. Sengupta, K. M. P. Raja, N. Shamala, P. Balaram, J. Am. Chem. Soc. 2005, 127, $16668-16674$; c) G. V. M Sharma, P. Nagedar, P. Jayaprakash, P. R. Krishna, K. V. S. Ramakrishna, A. C. Kunwar, Angew. Chem. 2005, 117, 6028-6032; Angew. Chem. Int. Ed. 2005, 44, $5878-5882$; d) G. Srinivasulu, S. K. Kumar, G. V. M. Sharma, 
A. C. Kunwar, J. Org. Chem. 2006, 71, 8395-8400; e) S. De Pol, C. Zorn, C. D. Klein, O. Zerbe, O. Reiser, Angew. Chem. 2004 116, 517-520; Angew. Chem. Int. Ed. 2004, 43, 511-514.

[7] a) D. Seebach, S. Abele, K. Gademann, B. Jaun, Angew. Chem. 1999, 111, 1700-1703; Angew. Chem. Int. Ed. 1999, 38, $1595-$ 1597; b) T. A. Martinek, G. K. Tóth, E. Vass, M. Hollósi, F. Fülöp, Angew. Chem. Int. Ed. Angew.Chem. Int. Ed. 2002, 41, $1718-1721$; c) S. Chandrasekhar, B. N. Babu, A. Prabhakara, A Sudhakar, M. S. Reddy, M. U. Kiran, B. Jagadeesh, Chem. Commun. 2006, 1548-1550; d) T. A. Martinek, I. M. Mándity, L. Fülöp, G. K. Tóth, E. Vass, M. Hollósi, E. Forró, F. Fülöp, J. Am. Chem. Soc. 2006, 128, 13539-13544.

[8] a) L. E. Townsley, W. A. Tucker, S. Sham, J. F. Hinton, Biochemistry 2001, 40,11676-11686; b) B. Di Blasio, M. Saviano, R. Fattorusso, A. Lombardi, C. Pedone, V. Valle, G. P. Lorenzi, Biopolymers 1994, 34, 1463-1468.

[9] I. A. Topol, S. K. Burt, E. Deretey, T. H. Tang, A. Perczel, A. Rashin, I. G. Csizmadia, J. Am. Chem. Soc. 2001, 123, $6054-$ 6060 .

[10] a) P. I. Arvidsson, L. Rueping, D. Seebach, Chem. Commun. 2001, 649-650; b) R. P. Cheng, W. F. DeGrado, J. Am. Chem. Soc. 2001, 123, 5162-5163; c) J. A. Kritzer et al., J. Am. Chem. Soc. 2005, 127, 167-178.

[11] a) T. D. W. Claridge, J. M. Goodman, A. Moreno, D. Angus, S. F. Barker, C. Taillefumier, M. P. Watterson, G. W. J. Fleet, Tetrahedron Lett. 2001, 42, 4251-4255; b) R. Threlfall, A. Davies, N. M. Howarth, J. Fisher, R. Cosstick, Chem. Commun. 2008, $585-587$.

[12] a) A. Hayen, M. A. Schmitt, F. N. Ngassa, K. A. Thomasson, S. H. Gellman, Angew. Chem. 2004, 116, 511-516; Angew.
Chem. Int. Ed. 2004, 43, 505-510; b) S. H. Choi, I. A. Guzei, L. C. Spencer, S. H. Gellman, J. Am. Chem. Soc. 2008, 130, 6544-6570; c) M. A. Schmitt, S. H. Choi, I. A. Guzei, S. H. Gellman, J. Am. Chem. Soc. 2006, 128, 4538-4539.

[13] G. N. Ramachandran, C. Ramakrishnan, V. Sasisekharan, J. Mol. Biol. 1963, 7, 95-99.

[14] A. Banerjee, P. Balaram, Curr. Sci. 1997, 73, 1067-1077.

[15] a) K. Mohle, R. Gunther, M. Thormann, N. Sewald, H. J. Hofmann, J. Biopolymers 1999, 50, 167-184; T. Beke, I. G. Csizmadia, A. Perczel, J. Comput. Chem. 2004, 25, 285-307.

[16] A. Bavoso, E. Benedetti, B. Di Blasio, V. Pavone, C. Toniolo, G. M. Bonora, Proc. Natl. Acad. Sci. USA 1986, 83, 1988-1992.

[17] S. H. Choi, I. A. Guzei, L. C. Spencer, S. H. Gellman, J. Am. Chem. Soc. 2008, 130, 6544-6570.

[18] T. A. Halgren, J. Comput. Chem. 1999, 20, 720-729.

[19] S. Chandrasekhar, G. P. K. Reddy, M. U. Kiran, C. Nagesh, B. Jagadeesh, Tetrahedron Lett. 2008, 49, 2969-2973.

[20] a) S. Zerkout, V. DuPont, A. Aubrey, J. Vidal, A. Collet, A. Vicherat, M. Marraud, Int. J. Pept. Protein Res. 1994, 44, $378-$ 387; b) S. Prasad, R. B. Rao, P. Balaram, Biopolymers 1995, 35, 11-20; c) C. Toniolo, G. M. Bonora, G. Stavropoulous, P. Cordopatis, D. Theodoropoulos, Biopolymers 1986, 25, 281289; d) S. Sakakibara, Biopolymers 1995, 37, 17-28.

[21] a) S. Chandrasekhar, B. Sarithaa, P. Naresh, M. Udayakiran, Ch. R. Reddy, B. Jagadeesh, Helv. Chim. Acta 2008, 91, $1267-$ 1276; b) D. Ranganathan, V. Haridas, S. Kurur, R. Nagaraj, E. Bikshapathy, A. C. Kunwar, A. V. S. Sarma, M. Vairamani, J. Org. Chem. 2000, 65, 365-374. 